find out the effect of percentages of carbon dioxide, a series of experiments was carried out on rabbits in the pharmacological laboratory with Professor Marshall and Dr. Macdonald. All the signs of surgical anaesthesia, including muscular relaxation, were produced in the rabbit with a concentration of 35 to 40 per cent. of carbon dioxide, and quiet anaesthesia continued as long as this percentage was maintained. The rapid replacement of carbon dioxide by oxygen, or the sudden removal of the rabbit to atmospheric air, gave rise to a clonic convulsion during the recovery from anaesthesia, whereas, if the carbon dioxide was slowly replaced by oxygen, no convulsion occurred. It appeared evident that the exciting cause of the convulsion was the excessive stimulation of the central nervous system of an anaesthetized animal by the rapid inrush of oxygen.

Mennell ${ }^{8}$ suggested that the convulsions were caused by deep ether anaesthesia and an excess of oxygen. In 1927 Pinson, ${ }^{9}$ who had had experience of a number of cases in Manchester, considered that the convulsions were due to modern methods of anaesthesia, which tend to the accumulation and rebreathing of carbon dioxide. It must be pointed out that closed and perhalation methods of ether anaesthesia have been in general use for many years, and more recently carbon dioxide has been administered in many thousands of surgical cases without giving any clinical evidence of convulsive phenomena, while convulsions occur during a simple open ether administration.

\section{Suppuration and Toxaemia}

In all these cases an acute suppurative process with a high degree of toxaemia or septicaemia was in operation. One case had a virulent pneumococcal peritonitis, one had a haemolytic streptococcal peritonitis, and one gave a pure culture of haemolytic streptococci from the pus and from the blood. In my judgement the degree of toxaemia or of septicaemia is of the greatest importance, and forms the chief factor in the causation of these convulsions.

Ether, containing acetaldehyde and peroxide in quantities known to be many times greater than was found in the ether used when convulsions occurred, has been administered by me to non-toxic patients without any clinical evidence of convulsive phenomena.

I have arrived at the conclusion that these convulsions owe their origin to two main factors. The essential and predisposing condition is acute toxaemia, and the exciting cause is ether, itself a toxic agent, which stimulates an increased circulation of blood loaded with toxins or bacteria, or both, to the central nervous system and initiates acute cerebral irritation. The severity of the convulsion is in proportion to the virulence and acuteness of the toxaemia or septicaemia, and may be aggravated by any impurities in the ether.

\section{Prophylactic Treatment}

The duration of the anaesthesia would appear to be an important element. In none of the cases did the convulsion appear until the anaesthesia had continued for at least fifteen minutes. In young patients, therefore, with acute suppuration, toxaemia; and high temperature the surgeon might well merely evacuate and drain, doing the least possible until the acute phase of the toxaemia has passed. This would reduce to a minimum the period of anaesthesia, the amount of the anaesthetic agent, and the sensory stimuli from the operation area to the central nervous system.

Aldehydes and peroxides in ether have undoubted toxic properties, and tend to inhibit normal oxidation in the nerve cells. The passage of gas and oxygen over or through ether causes it to deteriorate rapidly. This is a point of considerable importance, and ethcr which has been used with gas and oxygen should not be used in successive cases, more especially in children with acute toxaemia and high temperature. The purest ether from a bottle opened for the occasion is the ideal.

The treatment of the actual convulsion with inhalation of oxygen was inspired by the respiratory distress and cyanosis. It appeared to benefit the patient, and 90 per cent. of oxygen with 10 per cent. of carbon dioxide ${ }^{10}$ has been used and recommended to control the convulsion. The etiology, prevention, and treatment of these convulsions is still obscure, and demands further investigation.

Three patients have had convulsions since this article was written-two at the Sick Children's Hospital, and one, who died on the table, at the Royal Infirmary.

\section{References}

${ }^{1}$ Fairlie, H. P.: British Medical Journal, 1927, ii, 703.

2 Hornabrook, R. W.: Ibid., 1927, ii, 471.

3 Gwathmey, J. 'T.: Lancet, 19'27, i, 1369.

4 Svkes, W. S.: British Medical Journal, 1930, i, 1128.

5 Wesley Bourne: Anesthesia and Analgesia, vi, No. 3, 131

6 Wilson, S. R. : Lancet, 1927, i, 1117.

${ }^{7}$ C. J. S. T.: British Medical Journal, 1912, i, 843.

s Menneli, Z.: Proc. Roy. Soc. Med., xxi, No. 10, 1705.

9 Pinson, K. B.: British Medical Journal, 1927, i, 956.

10 Hewer, Langton: Ibid., 1927, ii, 703.

\section{UNILATERAL EXOPHTHALMOS FOLLOWING ADMINISTRATION OF THYROID EXTRACT}

BY

T. GILLMAN MOORHEAD, M.D., F.R.C.P.I.

CONSUltiNG PHYSICIAN, MERCER'S HOSPITAL, DUBLIN

The interesting point in the case reported below is the apparent production of exophthalmos by oral administration of thyroid extract, and the fact that the exophthalmos was unilateral.

Although physiologists as a body seem to agree that it is not possible to produce exophthalmos in animals by experimental administration of thyroid substance, there are some experiments on record which throw doubt on this conclusion. Edmunds ${ }^{1}$ quotes Cunningham ${ }^{2}$ to the effect that the latter succeeded in producing exophthalmos in rabbits by giving thyroid extract, and adds that he himself produced the same effect on six monkeys to whom he had given about one-half of a sheep's thyroid daily. The period over which this dose was maintained is not stated. In the same paper reference is made to the report by Béclère ${ }^{3}$ of a case of myxoedema in which the taking of excessive doses of thyroid extract was followed by a certain degree of exophthalmos, while in the discussion that followed the reading of Edmunds's paper Lawford referred to a case seen at Moorfields Hospital in which bilateral exophthalmos, better marked on the right than on the left side, was apparently the result of the excessive administration of thyroid extract. The condition must be rare, however, and is of undoubted interest from a physiological standpoint.

Mrs. M., aged 54, who was brought to me in March, 1927, had the following history. $U_{P}$ to 1924 she had enjoyed perfect health, but in that year she began to feel vaguely unwell and consulted a doctor, who told her that she was suffering from myxoedema. Thyroid extract was prescribed, and immediate improvement followed. Any attempt to discontinue the extract was followed by a return of ill-health. At the beginning of 1926 the dose of thyroid extract had been increased to $12 \frac{1}{2}$ grains daily, and this dose was taken continuously throughout that year and up to the date of her visit to me. Early in 1927 she did not feel well, and in February noticed for the first time that her right eye was much more prominent than her left. She immediately consulted an oculist, who, after a thorough examination, assured her that there was nothing the matter with her eye or orbital tissues, and expressed the opinion that she was suffering from Graves's disease with unilateral exophthalmos. She 
next consulted a rhinologist, who told her that her nasal sinuses were perfectly normal. An $x$-ray examination was carried out at this time also, and revealed nothing abnormal. Finally, as already stated, she consulted me.

On examination I found that she was suffering from obvious symptoms of thyroid intoxication, with tachycardia, pulse rate being 140, palpitation, extreme nervousness and restlessness, insomnia, and loss of weight. She refused to have her basal metabolism estimated, but calculation made from the pulse pressure formula gave an estimated metabolism of 118 . The right eye was extremely prominent, and showed a wellmarked von Graefe's sign. The left eye appeared normal. No vestige of a thyroid gland could be felt by the most careful palpation. After consideration the only possible diagnosis scemed to be that all the patient's symptoms, including the exophthalmos, were due to an overdosage of thyroid extract. In consequence, the extract was stopped, and the patient was put to bed for some time and treated with bromides. In the course of a couple of months the symptoms had largely disappeared, and after six months the patient was practically restored to health. As the general symptoms subsided, the exophthalmos diminished, but up to the date of my last seeing her-in June, 1928-the right eye was still somewhat more prominent than the left.

\section{The Sale of Thiyroid Products}

Although the object of this note is to call attention to the occasional production of ocular symptoms from thyroid administration, opportunity is taken of urging the necessity of introducing some restrictions in the sale of thyroid products. Since the earliest days of thyroid medication it has been recognized that overdosage can produce serious symptoms. These symptoms are attributed by some to the thyroid substance itself, and by others to decomposition products contained in extracts. However this may be, any physician of experience must have met with many cases in which long-standing illhealth with hyperthyroid symptoms has been caused by excess of this drug, and also certain acute cases in which sudden palpitation, giddiness, dyspnoea, and nervous terror have been brought about by prolonged overdosage. Möller, writing in the Acta Medica Scandinavica, has recently called attention to the subject, and suggests that thyroid substance should be put on the list of dangerous drugs. In most cases the fault lies not with the physician but with the patient. Patients learn that thyroid substance is efficacious in obesity, and without professional advice obtain thyroid tablets from a chemist, and, quite unaware of any possible harmful results, continue to take large doses for prolonged periods. If thyroìd substance could be obtained only on a doctor's prescription, and that only for a limited period, the present by no means uncommon ill results could be avoided.

\section{References}

${ }^{1}$ Edinunds: Experimental Exophthalmos and Enophthalmos, Trans, Ophth. Soc. of the United Kingdom, 1900, xx, 243.

${ }^{2}$ Cunningham: Journ. Exper. Med., 1898.

${ }^{3}$ Béclère: Gaz. des Hôp., October 16th, 1894.

\section{HALLUX VALGUS: A NOTE ON OPERATIVE TECHNIQUE}

BY

PAUL BERNARD ROTH, F.R.C.S.

From a large experience of the treatment of this deformity at the Orthopaedic Department of the Miller Hospital a routine operation has gradually evolved, which has been attended by such gratifying results that a description of it may be of interest.

\section{Choice of Patient}

Any patient who has a painful bunion over the inner side of the big toe joint, with deflection of the toe outwards, causing the second toe to override it, is judged suitable. This is the typical condition for which the patient seeks relief. Sometimes it is the unsightly appearance, sometimes the pain, sometimes the impossibility of getting shoes to fit, which sends the patient to hospital: -sometimes all three together. The fact that the bunion is acutely inflamed does not contraindicate operation; it is an additional reason for it.

Age is no bar. The trouble may be present in a child aged 12 or in a man 60 or over; all react to the operation in just the same way, and are entirely relieved. Convalescence may be slightly longer in an elderly personthat is all.

The nature of the patient's occupation is certainly of influence in coming to a decision. One does not operate for choice on a person who will go back to employment which requires prolonged standing. Yet where no other work can be found, as in the case of a nurse, the operation may be performed with confidence, provided the period of convalescence is longer than usual. I should refuse, however, to operate on a toe-dancer or a professional footballer.

Women who wear high heels ask if they will be able to do so afterwards. In my experience there has never been any difficulty about this; the high heel position is always perfectly comfortable after the operation has been performeci.

\section{Preparation of Patient}

After thorough washing with soap and water, with special attention to the nails and nail folds, the feet are painted with tincture of iodine and wrapped in a sterile towel. The painting with iodine is repeated on the table. If the bunion is inflamed, the inflammation must be allowed to subside by rest in bed for two or three days. Under no circumstances is the operation performed in the presence of inflammation.

\section{The Operation}

No tourniquet is used. The foot lies on its outer side, and a horizontal incision 2 inches long, parallel with the length of the toe, is made through the bunion, extending equally beyond it in both directions; it is planned to lie rather nearer the dorsum than the sole. The knife cuts down on to the neck of the metatarsal and through the layers of the bunion, exposing the head, the line of the joint, and the base of the phalanx, all in one sweep. The neck is cleared of periosteum by inserting two periosteal detachers in the line of the incision, one detaching everything above and levering it up, the other detaching everything below and levering it down. These two detachers are held with their points at right angles to each other by an assistant, and the now tense capsule is freed from the head by a few touches of the knife. Finally, the capsule is cut through vertically, opposite the joint interval, exposing the head completely. The blades of the bone-cutting forceps are insinuated above and below the neck one at a time, the detachers being separately withdrawn to make way for them, and are adjusted as close to the head as possible, with their bevelled edges turned towards it. Only the head is removed, not half an inch of the shaft as well. When the blades are in position the neck is cut through, and the severed head levered out with the closed bone-cutting forceps and the two detachers, so that it is grasped with Lane's small bone-holding forceps, twisted off, and removed. The skin edges are brought together with tissue forceps, sutured with continuous horsehair, and the operation finished by painting with iodine, inserting a gauze pad between the first and second toes, and applying a gauze dressing. 